\title{
RamB, a Novel Transcriptional Regulator of Genes Involved in Acetate Metabolism of Corynebacterium glutamicum
}

\author{
Robert Gerstmeir, ${ }^{1}$ Annette Cramer, ${ }^{1}$ Petra Dangel, ${ }^{1}$ Steffen Schaffer, ${ }^{2}$ \\ and Bernhard J. Eikmanns ${ }^{1 *}$ \\ Department of Microbiology and Biotechnology, University of Ulm, $89068 \mathrm{Ulm},{ }^{1}$ and Institute of Biotechnology 1, \\ Research Center Jülich, D-52425 Jülich, ${ }^{2}$ Germany
}

Received 28 October 2003/Accepted 16 January 2004

\begin{abstract}
The adaptation of Corynebacterium glutamicum to acetate as a carbon and energy source involves transcriptional regulation of the pta-ack operon coding for the acetate-activating enzymes phosphotransacetylase and acetate kinase and of the $a c e A$ and $a c e B$ genes coding for the glyoxylate cycle enzymes isocitrate lyase and malate synthase, respectively. Deletion and mutation analysis of the respective promoter regions led to the identification of highly conserved 13-bp motifs (AA/GAACTTTGCAAA) as cis-regulatory elements for expression of the pta-ack operon and the aceA and aceB genes. By use of DNA affinity chromatography, a 53-kDa protein specifically binding to the promoter/operator region of the pta-ack operon was purified. Mass spectrometry and peptide mass fingerprinting identified the protein as a putative transcriptional regulator (which was designated RamB). Purified His-tagged RamB protein was shown to bind specifically to both the pta-ack and the aceA/aceB promoter/operator regions. Directed deletion of the ramB gene in the genome of $C$. glutamicum resulted in mutant strain RG1. Whereas the wild type of $C$. glutamicum showed high-level specific activities of acetate kinase, phosphotransacetylase, isocitrate lyase, and malate synthase when grown on acetate and low-level specific activities when grown on glucose as sole carbon and energy sources, mutant RG1 showed high-level specific activities with all four enzymes irrespective of the substrate. Comparative transcriptional cat fusion experiments revealed that this deregulation takes place at the level of transcription. The results indicate that RamB is a negative transcriptional regulator of genes involved in acetate metabolism of $C$. glutamicum.
\end{abstract}

Corynebacterium glutamicum is a gram-positive bacterium widely used in the industrial production of amino acids (32). The organism grows on a variety of carbohydrates and organic acids as single or combined sources of carbon and energy. Among these substrates are glucose and acetate, both of which can also serve as substrates for amino acid production $(29,32)$. Growth on and amino acid production from acetate requires its activation to acetyl-coenzyme A (acetyl-CoA) and, when acetate is the sole carbon and energy source, also requires the operation of the glyoxylate cycle as an anaplerotic pathway. Acetate activation in C. glutamicum is accomplished by the combined activities of acetate kinase (AK) and phosphotransacetylase (PTA) (50). AK activates acetate in an ATP-dependent reaction to acetyl phosphate, which is subsequently converted to acetyl-CoA by PTA. Both enzymes from $C$. glutamicum and their regulation were studied, and mutants defective in either or both of the enzymes were analyzed (43, 60 ). Isocitrate lyase (ICL) and malate synthase (MS), the key enzymes of the glyoxylate cycle, have also been intensively studied using $C$. glutamicum $(41,42,50)$. ICL catalyzes the cleavage of isocitrate to succinate and glyoxylate, and MS condenses glyoxylate with acetyl-CoA to give malate. Both enzymes of $C$. glutamicum have been biochemically characterized, and it turned out that both are subject to allosteric regulation by several intermediates of the central metabolism $(41,42)$.

\footnotetext{
* Corresponding author. Mailing address: Department of Microbiology and Biotechnology, University of Ulm, 89069 Ulm, Germany. Phone: 49731502 2707. Fax: 49731502 2710. E-mail: bernhard .eikmanns@biologie.uni-ulm.de.
}

The $C$. glutamicum genes encoding ICL and MS (ace $A$ and $a c e B$, respectively), as well as those coding for the acetateactivating enzymes AK and PTA (ack and pta, respectively), have been characterized, and all four enzymes have been shown by gene-directed mutagenesis and analysis of mutants to be essential for the growth of C. glutamicum on acetate (14, 41, 42, 43). The AK and PTA genes form an operon with pta upstream of ack, and recent primer extension experiments identified two transcriptional start sites (Ts1 and Ts2) 160 and $47 \mathrm{bp}$ upstream of the translation initiation codon of the pta gene and, thus, two promoters for the pta-ack operon. The $C$. glutamicum ace $A$ and $a c e B$ genes are clustered on the chromosome and are separated by $597 \mathrm{bp}$ and transcribed in divergent directions from transcriptional start sites $112 \mathrm{bp}$ upstream of the ace $A$ gene and 466 and 468 bp upstream of the $a c e B$ gene, respectively.

Further studies showed that AK, PTA, ICL, and MS are coordinately and specifically up-regulated in the presence of acetate in the growth medium, and transcriptional fusion and Northern blot experiments revealed that this regulation is mainly due to transcriptional control of the respective genes $(43,60)$. In addition, recent genome-wide expression analyses of $C$. glutamicum cells grown on glucose and on acetate substantiated the idea of this transcriptional regulation of the ace $A, a c e B$, pta, and $a c k$ genes $(14,21,35)$. In accordance with induction or repression of these genes by a common regulator protein(s), in front of the genes we observed highly conserved 13-bp motifs (AA/GAACTTTGCAAA) showing a dyad symmetry at one end (underlined) (14). These motifs are centered 50 and 47 bp upstream of Ts1 and Ts2 of the pta-ack operon 
TABLE 1. Plasmids and oligonucleotides used in this study

\begin{tabular}{|c|c|c|}
\hline Plasmid or oligonucleotide & Relevant characteristic(s) or sequence ${ }^{a}$ & Source, reference, or purpose ${ }^{b}$ \\
\hline \multicolumn{3}{|c|}{ 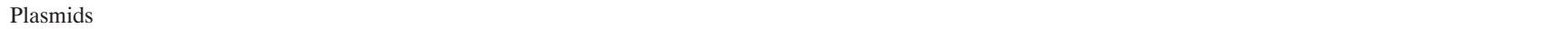 } \\
\hline pET2 & Promoter probe vector carrying the promoterless cat gene, $\mathrm{Km}^{\mathrm{rc}}$ & 57 \\
\hline pRob19, pRob22, pRob23 & $\begin{array}{l}\text { pET2 containing } 895-, 667-, \text { and } 478-b p \text { inserts of pta-ack promoter } \\
\text { region, respectively }\end{array}$ & This work \\
\hline pRob30, pRob31, pRob32 & $\begin{array}{l}\text { pET2 containing the } 895 \text {-bp pta-ack promoter fragment with } \\
\text { mutagenized 13-bp motifs M1 and/or M2 (Fig. 1) }\end{array}$ & This work \\
\hline pRob1 and pRob10 & $\begin{array}{l}\text { pET2 containing } 605-\mathrm{bp} \text { ace } A \text { and 584-bp } a c e B \text { promoter fragments, } \\
\text { respectively }\end{array}$ & This work \\
\hline pRob26 and pRob28 & $\begin{array}{l}\text { pET2 containing 605-bp ace } A \text { and 584-bp aceB promoter fragments } \\
\text { with mutagenized 13-bp motif }\end{array}$ & This work \\
\hline pET29a & $\mathrm{Km}^{\mathrm{r}}$, f1 origin, $6 \times$ histidyl fusion vector & Calbiochem-Novabiochem, Schwalbach, Germany \\
\hline pET29-RamBx6His & pET29 containing the $r a m B$ structural gene & This work \\
\hline pK19mobsacB & $\mathrm{Km}^{\mathrm{r}}$, mobilizable (oriT), oriV & 46 \\
\hline pK19 $\Delta \mathrm{ramB}$ & $\begin{array}{l}\text { pK19mobsacB carrying a } 1,113-b p \text { insert with a truncated } \operatorname{ramB} \\
\text { gene, shortened by } 776 \mathrm{bp}\end{array}$ & This work \\
\hline \multicolumn{3}{|l|}{ Oligonucleotides } \\
\hline pta-bio & 5'-Biotin-TEG-CAGATTTGTCACGCTGCG-3' & $\begin{array}{l}\text { Biotinylated forw. primer for pta-ack promoter/ } \\
\text { operator probe }\end{array}$ \\
\hline pta-16 & 5'-TTCGTCCGCCTTGCGTACAG-3' & Rev. primer for pta-ack promoter/operator probe \\
\hline aceb-bio & 5'-Biotin-TEG-TCCTTAAGTGCTGATTCG-3' & $\begin{array}{l}\text { Biotinylated forw. primer for } a c e A / a c e B \\
\text { promoter/operator probe }\end{array}$ \\
\hline$a c e b \mathrm{R} 1$ & 5'-AGGTCACACCTTCGAAACC-3' & $\begin{array}{l}\text { Rev. primer for } a c e A / a c e B \text { promoter/operator } \\
\text { probe }\end{array}$ \\
\hline $\mathrm{ramBf}$ & 5'-GGAATTCCATATGGGAAAGACCTATGTGGGGTCC-3' & Forw. primer for pET29-RamBx6His (NdeI) \\
\hline $\operatorname{ram} \mathrm{Br}$ & 5'-CCCAAGCTTGGGGTACGGCGCGATAGTGGATTCG-3' & Rev. primer for pET29-RamBx6His (HindIII) \\
\hline $\operatorname{ram} B 1$ & $5^{\prime}$-CCCAAGCTTGGGCAACTGGCTGTTTAGAGAC-3' & Primer for $\operatorname{ramB}$ deletion (HindIII) \\
\hline $\operatorname{ramB2}$ & 5'-TTCGCGGATCCCGCTTGCAGATAAGCCAAGG-3' & Primer for $\operatorname{ramB}$ deletion (BamHI) \\
\hline $\operatorname{ramB3}$ & 5'-CGGGATCCGCGAAGAAAAATCCGGCTACGAC-3' & Primer for $r a m B$ deletion (BamHI) \\
\hline $\mathrm{ramB} 4$ & 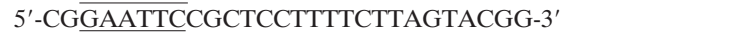 & Primer for $r a m B$ deletion (EcoRI) \\
\hline ptaack2 & 5'-TGCTGTCGACCCTCCATGATACGTGGTAAG-3' & $\begin{array}{l}\text { Forw. primer for pRob19, pRob30, pRob31, } \\
\text { pRob32 (SalI) }\end{array}$ \\
\hline ptaack3 & 5'-AAGCGTCGACTTGAGATCGGTTTG-3' & Forw. primer for pRob22 (SalI) \\
\hline ptaack $3 \mathrm{~A}$ & 5'-ACGCGTCGACGTCAGCTCTGATCACCACG-3' & Forw. primer for pRob23 (SalI) \\
\hline ptaR1 & 5'-GTGGGGATCCCATCAAGATGCGGTCG-3' & $\begin{array}{l}\text { Rev. primer for pRob19, pRob22, pRob23, } \\
\text { pRob30, pRob31, pRob32 (BamHI) }\end{array}$ \\
\hline acea $\mathrm{A}$ & 5'-ACGCGTCGACAACAGTTCCTGTTCAG-3' & Forw. primer for pRob1, pRob26 (SalI) \\
\hline acea $\mathrm{R} 2$ & 5'-CGGGATCCCGTAAGTGCTGATTCGCAATGG-3' & Rev. primer for pRob1, pRob26 (BamHI) \\
\hline aceb1 & 5'-TCAAGTCGACTTCCTTAAGTGCTGATTCG-3' & Forw. primer for pRob10, pRob28 (SalI) \\
\hline$a c e b \mathrm{R} 4$ & 5'-CGGGATCCCGCTCCTTTTAAAGCATGGG-3' & Rev. primer for pRob10, pRob28 (BamHI) \\
\hline ptabox1mut1 & $5^{\prime}$-GCTAAAAACGAGGCAAAGGG-3' & SOE forw. primer for pRob31, pRob32 (SalI) \\
\hline ptabox1mut1 R & 5'-CCCTTTGCCTEGTTTTTAGC-3' & SOE rev. primer for pRob31, pRob32 (BamHI) \\
\hline ptabox 2 mut 1 & 5'-AAACGAG $\overline{\overline{G C G}}$ AGCCGGGCTGTACGCAAGG-3' & SOE forw. primer for pRob30, pRob32 (SalI) \\
\hline ptabox 2 mut1 $\mathrm{R}$ & $5^{\prime}$-CGGCE $\underline{\overline{T C G}}$ CC $\overline{\overline{T C}}$ GTTTATTTTGTAATTTTCAAACC-3' & SOE rev. primer for pRob30, pRob32 (BamHI) \\
\hline aceboxmut1 & 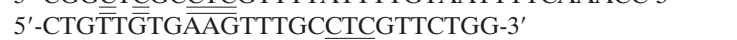 & SOE forw. primer for pRob26, pRob28 (SalI) \\
\hline aceboxmut1 R & $5^{\prime}$-CCAGAACGAGGCAAA $\overline{\overline{C T T}}$ CACAACAG-3' & SOE rev. primer for pRob26, pRob28 (BamHI) \\
\hline
\end{tabular}

${ }^{a}$ Mutagenized nucleotides are indicated with double underlines; restriction sites are indicated with single underlines.

${ }^{b}$ Forw., forward; rev., reverse.

${ }^{c} \mathrm{Km}$, kanamycin.

and 94 bp upstream of the ace $A$ or 74 bp downstream of the $a c e B$ transcriptional start sites. Although a lot of biochemical and genetic knowledge with respect to the acetate metabolism of $C$. glutamicum and its regulation has been accumulated, however, the basic mechanism of transcriptional regulation of the enzymes involved has not been elucidated so far and the relevance of the 13-bp motifs remained unclear.

In the present study we proved the relevance of the 13-bp motifs found in front of the pta-ack operon and in the intergenic region between $a c e A$ and $a c e B$ for the regulation of these genes. Using the promoter/operator site of the pta-ack operon, we enriched a DNA-binding protein by DNA affinity chromatography. Matrix-assisted laser desorption ionization-time of flight (MALDI-TOF) analysis was used to identify this protein as a very likely candidate for a regulatory protein. The regulatory function of this protein was studied by DNA-binding assays and by enzyme and promoter activity analysis of a genedirected mutant of $C$. glutamicum. The results indicate that the protein represents a novel regulatory protein which, during growth of the organism in the absence of acetate, acts as a transcriptional repressor of both the $a c e A$ and $a c e B$ gene cluster and the pta-ack operon. Furthermore, we discuss the relevance of the 13-bp motif as a cis-regulatory element of further genes coding for enzymes involved in the central metabolism of C. glutamicum.

\section{MATERIALS AND METHODS}

Bacteria, plasmids, oligonucleotides, and culture conditions. Escherichia coli DH5 $\alpha$ (20), E. coli BL21 (10), and the wild-type (WT) strain of C. glutamicum ATCC13032 were employed. Data regarding the plasmids (and their relevant characteristics and sources) and oligonucleotides used in this study are given in Table 1. The minimal medium used for C. glutamicum has been described previously (11) and contained $1 \%(\mathrm{wt} / \mathrm{vol})$ acetate, lactate, ribose, ethanol, citrate, or glucose. TY medium $(2 \times)(45)$ was used as a complex medium for $C$. glutamicum and for E. coli. When appropriate, kanamycin $\left(50 \mu \mathrm{g} \mathrm{ml}^{-1}\right)$ was added to the medium. If not stated otherwise, $C$. glutamicum was grown aerobically at $30^{\circ} \mathrm{C}$ and $\mathrm{E}$. coli was grown aerobically at $37^{\circ} \mathrm{C}$ as $50-\mathrm{ml}$ cultures in 500-ml baffled Erlenmeyer flasks on a rotary shaker at $120 \mathrm{rpm}$.

DNA preparation and transformation. The isolation of chromosomal DNA and of plasmids from C. glutamicum was performed as described previously (12), 
and plasmid isolation from E. coli was carried out according to the method of Birnboim (2). DNA transfer into $C$. glutamicum was performed by electroporation, and recombinant strains were selected on LBBHIS agar plates containing kanamycin $\left(15 \mu \mathrm{g} \mathrm{ml}^{-1}\right)$ (55). Transformation of E. coli was carried out with competent cells according to the method of Inoue et al. (28).

PCR techniques. PCR experiments were performed in a Biometra personal cycler (Biotron, Göttingen, Germany). Amplification of DNA was carried out with Vent-Polymerase (New England Biolabs, Schwalbach, Germany). Buffers and deoxynucleoside triphosphates were taken from MBI-Fermentas (St. LeonRot, Germany). Oligonucleotides (primers) were obtained from MWG-Biotech (Ebersberg, Germany). Cycling times and temperatures were chosen according to fragment length and primer constitution. PCR products were separated on agarose gels and purified using a Nucleospin extract kit (Macherey Nagel, Düren, Germany)

DNA manipulation and Southern hybridization. Restriction enzymes, T4 DNA ligase, calf intestinal phosphatase, RNaseA, proteinase K, and Taq polymerase were obtained from MBI-Fermentas and used as instructed by the manufacturer. DNA purification after restriction digestions was performed by separation on agarose gels and purification with a Nucleospin extract kit (Macherey Nagel). DNA hybridization experiments were performed as previously described (41). The complete $r a m B$ gene was amplified and labeled with digoxigenin-dUTP by PCR and used as a probe. Labeling, hybridization, washing, and detection were performed using a nonradioactive DNA labeling and detection kit and instructions from Roche Diagnostics (Penzberg, Germany). Site-directed mutagenesis of the 13-bp motifs was performed by use of overlap extension PCR according to Ho et al. (24). The primers taken for the introduction of base pair changes are listed in Table 1.

DNA affinity purification. The purification of DNA-binding proteins was performed essentially as described previously (13). Briefly, the pta-ack promoter/ operator probes were generated by PCR using plasmid pRob19 (native probe) or pRob32 (probe mutagenized in both 13-bp motifs) and oligonucleotides pta-bio and $p t a-16$, the former being tagged with biotin via a TEG linker (MWGBiotech). Unincorporated oligonucleotides were removed by twofold ultrafiltration of the sample with microcon-30 concentrators (Amicon, Witten, Germany). About 100 pmol of biotin-labeled PCR product was coupled to $3 \mathrm{mg}$ of Dynabeads streptavidin (Dynal, Oslo, Norway), and uncoupled DNA was removed by magnetic separation following the manufacturer's protocol. The coupled Dynabeads were stored at $4^{\circ} \mathrm{C}$ for at most 1 week. Directly before incubation with the C. glutamicum crude extracts (see below), the coupled Dynabeads were equilibrated with $300 \mu \mathrm{l}$ of binding buffer (20 mM Tris- $\mathrm{HCl}$ [pH 7.5], 1 mM EDTA, 1 $\mathrm{mM}$ dithiothreitol, $100 \mathrm{mM} \mathrm{NaCl}, 10 \%$ [vol/vol] glycerol, $0.05 \%$ [vol $/ \mathrm{vol}]$ Triton $\mathrm{X}-100, \mathrm{pH} 8.0)$ for $2 \mathrm{~min}$.

Cultures $(500 \mathrm{ml})$ of $C$. glutamicum were grown on minimal medium, harvested at an optical density at $600 \mathrm{~nm}\left(\mathrm{OD}_{600}\right)$ of about 5 , washed with 1 volume of TN buffer (50 mM NaCl, $50 \mathrm{mM}$ Tris-HCl, $\mathrm{pH} 7.6)$, and suspended in $6 \mathrm{ml}$ of disruption buffer (50 mM Tris- $\mathrm{HCl}$ [pH 7.6], $1 \mathrm{mM}$ dithiothreitol, $10 \mathrm{mM} \mathrm{MgCl}_{2}$, $1 \mathrm{mM}$ EDTA, $10 \%$ [vol/vol] glycerol, $10 \mu \mathrm{M}$ phenylmethylsulfonyl fluoride). Aliquots $(1 \mathrm{ml})$ of the cell suspension were filled in 2-ml screw-cap vials and disrupted with a RiboLyser as described above. Glass beads and cellular debris were removed by centrifugations at $13,000 \times g$ and $4^{\circ} \mathrm{C}$ for $10 \mathrm{~min}$ and at 45,000 $\times g$ and $4^{\circ} \mathrm{C}$ for $60 \mathrm{~min}$. The supernatant was dialyzed for $5 \mathrm{~h}$ using $20 \%$ (wt/vol) PEG 20,000 in disruption buffer and Visking dialysis tubes (Serva, Heidelberg, Germany) with a pore size of $25 \AA$. The dialyzed crude extract (about $500 \mu \mathrm{l}$ ), together with $10 \mu \mathrm{l}$ of competitor DNA (herring sperm DNA) $(10 \mathrm{mg} / \mathrm{ml})$, was incubated with the coupled Dynabeads for $2 \mathrm{~h}$ at room temperature while being shaken at $350 \mathrm{rpm}$. Unbound proteins were removed using magnetic separation with a magnet particle concentrator (Dynal) and by being washed twice with 300 $\mu \mathrm{l}$ of binding buffer. DNA-bound proteins were eluted with $20 \mu \mathrm{l}$ of binding buffer containing $200 \mathrm{mM} \mathrm{NaCl}$. Eluted fractions were collected and subjected to sodium dodecyl sulfate-polyacrylamide gel electrophoresis (SDS-PAGE) using the technique of Laemmli (31). Gels were subsequently stained using a colloidal Coomassie blue staining kit (Novex, Frankfurt/Main, Germany).

Construction of plasmids for the synthesis and preparation of hexahistidyltagged RamB fusion protein. Vector pET29a was used for the synthesis of the hexahistidyl-tagged RamB fusion protein. The $\operatorname{ramB}$ gene was amplified from chromosomal DNA of $C$. glutamicum WT by PCR with the primers ramBf and $\mathrm{ramBr}$ (Table 1). The PCR product was digested by NdeI and HindIII, ligated into the NdeI/HindIII-restricted plasmid pET29a, and transformed into E. coli BL21. The synthesis of the RamB fusion protein was induced in recombinant $E$. coli BL21 (pET29-RamBx6His) by the addition of $1 \mathrm{mM}$ IPTG (isopropyl- $\beta$-Dthiogalactopyranoside) after the culture had reached an OD of 0.6. The cells were grown for $4 \mathrm{~h}$, harvested, and disrupted using a French pressure cell. Purification of the fusion protein was performed using $\mathrm{Ni}^{2+}$ affinity chromatog- raphy according to the instructions of Qiagen (Hilden, Germany). For desalting, the RamB fusion protein was loaded onto an equilibrated PD-10 column (Amersham Biosciences) and eluted with $3.5 \mathrm{ml}$ of elution buffer (50 mM Tris- $\mathrm{HCl}$ [pH 7.6], $10 \mathrm{mM} \mathrm{MgCl} 2,1 \mathrm{mM}$ EDTA). The fusion protein was then directly used for the promoter/operator binding assay.

Promoter/operator binding assays with hexahistidyl RamB fusion protein. The binding of the His-tagged RamB protein to the pta-ack and aceA/aceB promoter/operator regions was tested by DNA affinity chromatography using the DNA probes indicated in Fig. 1A and Fig. 2A, respectively. The aceA/aceB probe was generated by PCR using plasmid pRob1 (native probe) or pRob26 (probe with mutagenized 13-bp motif) and oligonucleotides $a c e B$-bio and $a c e b \mathrm{R} 1$, the former being tagged with biotin. Generation of the pta-ack probe, purification of the PCR products, coupling to the Dynabeads streptavidin, and equilibration of the coupled Dynabeads were performed (with DNA affinity purification) as described above. RamB fusion protein (about $50 \mu \mathrm{g}$ in $125 \mu \mathrm{l}$ ) was incubated with the coupled Dynabeads for $1 \mathrm{~h}$ at room temperature with shaking at $350 \mathrm{rpm}$ and an amplitude of $5 \mathrm{~mm}$. Unbound protein was removed by magnetic separation and washing with $300 \mu \mathrm{l}$ of binding buffer (containing $50 \mathrm{mM} \mathrm{NaCl}$ ). Subsequent elution was done with binding buffer containing 100, 200, or $1 \mathrm{M}$ $\mathrm{NaCl}(20 \mu \mathrm{l}$ each; magnetic separation was performed after each step). The eluted fractions $(10 \mu \mathrm{l}$ each) were subjected to SDS-PAGE, and gels were stained with Coomassie.

Construction of a ramB mutant. To construct a $\operatorname{ramB}$ mutant of $C$. glutamicum, two DNA fragments were generated by PCR using oligonucleotide pair $\operatorname{ramB1}$ and $\operatorname{ramB2}$ and oligonucleotide pair ramB3 and ramB4. Fragment 1 covers 434 bp upstream of $r a m B$ and $83 \mathrm{bp}$ of the $5^{\prime}$ end of $\operatorname{ram} B$, and fragment 2 covers the $3^{\prime}$ end of $\mathrm{ramB}$ (from bp 859) and 10 bp downstream of the TAA stop codon. The two fragments were ligated using the PCR-generated BamHI restriction sites, thereby shortening $\mathrm{ramB}$ in its $5^{\prime}$ coding region by $775 \mathrm{bp}$ (from position 84 to 858 ) and creating a 648-bp open reading frame devoid of a functional helix-turn-helix (HTH) motif. Using the 5' HindIII and 3' EcoRI restriction sites, the construct was ligated into pK19mobsacB and transformed into $C$. glutamicum by electroporation. The chromosomal deletion within the ramB gene was introduced into the $C$. glutamicum genome by homologous recombination (double crossover) according to a protocol described by Schäfer et al. (46). The deletion in the resulting C. glutamicum RG1 strain was confirmed by PCR (data not shown) and by Southern blot analysis. For the latter, BamHIrestricted chromosomal DNA from $C$. glutamicum WT and $C$. glutamicum $\triangle \mathrm{ram} B$ strains was hybridized to a labeled $\operatorname{ramB}$ probe covering the entire open reading frame, resulting in two signals of about 0.8 and $4 \mathrm{~kb}$ with the DNA from the ramB mutant and one signal of about $5.6 \mathrm{~kb}$ with the DNA from the WT strain.

Construction of $\boldsymbol{c a t}$ fusions. The promoter probe vector pET2 was used for construction of transcriptional fusions of the pta-ack promoter region and of the aceA/aceB intergenic region to the promoterless cat gene. The promoter fragments were generated by PCR using primers tagged with SalI and BamHI restriction sites and cloned directed in front of the cat gene in pET2. Point mutations were introduced into the promoter fragments by overlap extension PCR (24). Successful cloning and mutagenesis was verified by sequencing. The primers used for the promoter constructs are listed in Table 1.

Enzyme assays. To determine enzyme activities in cell extracts, $C$. glutamicum cells were grown in minimal medium to the exponential growth phase, washed twice in $20 \mathrm{ml}$ of $50 \mathrm{mM}$ Tris- $\mathrm{HCl}$ buffer ( $\mathrm{pH} 7)$, and resuspended in $1 \mathrm{ml}$ of the same buffer containing $10 \mathrm{mM} \mathrm{MgCl}_{2}, 1 \mathrm{mM}$ EDTA, $1 \mathrm{mM}$ dithiothreitol (except when used for determination of chloramphenicol acetyltransferase [CAT] activity), and 30\% (vol/vol) glycerol. The cell suspension was placed into 2-ml screwcap vials together with $250 \mathrm{mg}$ of glass beads (Sigma-Aldrich) (150 to $212 \mu \mathrm{m}$ ) and subjected (six times for $25 \mathrm{~s}$ ) to mechanical disruption with a RiboLyser (Hybaid, Heidelberg, Germany) (setting, 6.5) at $4^{\circ} \mathrm{C}$ with intermittent cooling on ice for $2 \mathrm{~min}$. After disruption, glass beads and cellular debris were removed by two consecutive centrifugation steps $\left(13,000 \times g, 4^{\circ} \mathrm{C}, 10 \mathrm{~min}\right.$, and $45,000 \times g$, $4^{\circ} \mathrm{C}, 60 \mathrm{~min}$ ) and the supernatant was used for the assays. The biuret method (15) was used (with bovine serum albumin as a standard) to determine protein concentrations.

CAT activity was assayed photometrically at $412 \mathrm{~nm}$ in $1 \mathrm{ml}$ of $100 \mathrm{mM}$ Tris- $\mathrm{HCl}$ ( $\mathrm{pH}$ 7.8)-1 mM 5,5'-dithiobis(2-nitrobenzoic acid)-0.1 mM acetylCoA-0.25 mM chloramphenicol as described by Shaw (49). One unit of CAT activity is defined as $1 \mu \mathrm{mol}$ of chloramphenicol acetylated per min at $37^{\circ} \mathrm{C}$.

AK activity was analyzed in the acetyl phosphate-forming direction in $1 \mathrm{ml}$ of $70 \mathrm{mM}$ Tris- $\mathrm{HCl}$ ( $\mathrm{pH}$ 7.6)-50 mM MgCl $2-3 \mathrm{mM}$ ATP-3 mM phosphoenolpyruvate- 0.3 mM NADH-7 U of pyruvate kinase- $10 \mathrm{U}$ of lactate dehydrogenase-340 $\mathrm{mM}$ acetate (as a substrate) as described by Van Dyk and LaRossa (56). One unit of AK activity is defined as $1 \mu \mathrm{mol}$ of $\mathrm{NADH}$ consumed per min at $30^{\circ} \mathrm{C}$. 


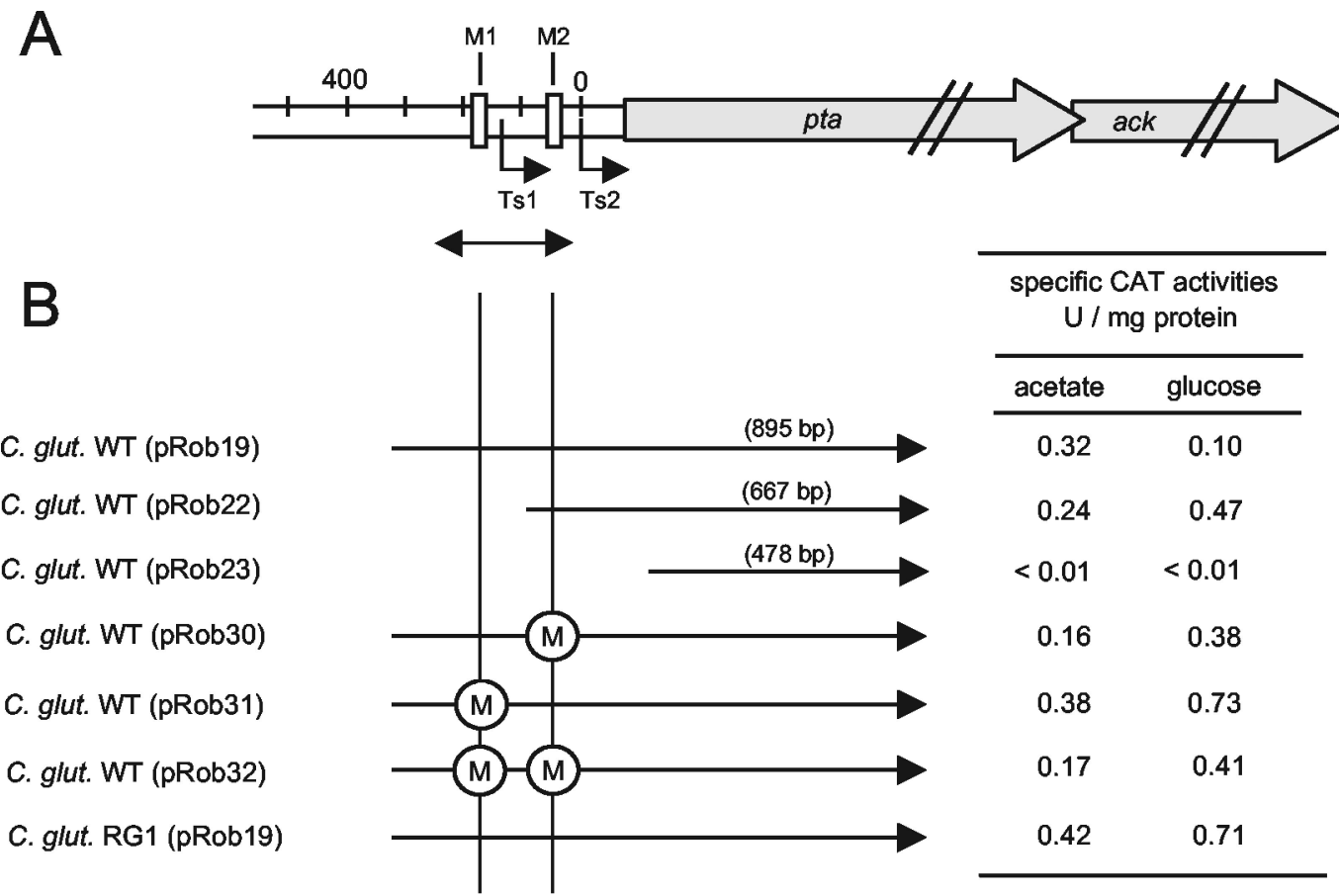

FIG. 1. Genomic locus of the pta-ack promoter region (A) and specific promoter activities of pta-ack promoter fragments in cells of $C$. glutamicum WT and ramB mutant RG1 strains grown in minimal medium containing acetate or glucose as carbon and energy sources (B). (A) The transcriptional start sites are indicated as Ts1 and Ts2; the 13-bp motifs are indicated as M1 and M2. The promoter/operator probe used for DNA affinity purification and for binding assays with purified His-tagged RamB protein is indicated by a double-headed arrow. (B) The promoter activity values represent specific activities of CAT determined using cell extracts of $C$. glutamicum (C. glut.) strains carrying the various promoter fragments (pRob19, pRob22, pRob23, pRob30, pRob31, and pRob32) in plasmid pET2. The respective fragments are indicated by arrows. The circled "M"s indicate that the respective 13-bp motifs were destroyed by mutation. The promoter activity values given represent averages of at least three independent cultivations and two determinations per experiment.

PTA activity was assayed by monitoring the conversion of acetyl phosphate to acetyl-CoA according to a modified method described by Brown et al. (4). In a final volume of $1 \mathrm{ml}$, the assay contained $100 \mathrm{mM}$ Tris- $\mathrm{HCl}(\mathrm{pH} 7.6), 5 \mathrm{mM}$ $\mathrm{MgCl}_{2}, 0.5 \mathrm{mM}$ cysteine, $20 \mathrm{mM} \mathrm{NH} \mathrm{NH}_{4}, 3 \mathrm{mM} \mathrm{CoA}$, and $20 \mathrm{mM}$ acetyl phosphate. The formation of acetyl-CoA was monitored photometrically at $232 \mathrm{~nm}$. One unit of PTA activity corresponds to $1 \mu \mathrm{mol}$ of acetyl-CoA formed per min at $30^{\circ} \mathrm{C}$.

ICL activity was assayed by measuring the conversion of the formed glyoxylate to glycolate using lactate dehydrogenase I and monitoring the decrease of $\mathrm{NADH}$ at $340 \mathrm{~nm}$ (58). The assay was performed in $1 \mathrm{ml} 50 \mathrm{mM}$ MOPS (pH 7.3)-5 mM dithiothreitol-15 mM $\mathrm{MgCl}_{2}-1 \mathrm{mM}$ EDTA-5 mM D-threo-isocitrate- $0.2 \mathrm{mM}$ NADH- $8 \mathrm{U}$ of lactate dehydrogenase (pig heart isoenzyme I). One unit of ICL activity corresponds to $1 \mu \mathrm{mol}$ of glyoxylate formed per min at $30^{\circ} \mathrm{C}$.

MS activity was assayed, following the decrease of acetyl-CoA at $232 \mathrm{~nm}$ in 1 $\mathrm{ml}$ of $50 \mathrm{mM}$ Tris- $\mathrm{HCl}(\mathrm{pH} 7.6)-40 \mathrm{mM} \mathrm{MgCl} 2-0.24 \mathrm{mM}$ acetyl-CoA-2 mM glyoxylate, according to a modified method described by Dixon and Kornberg (9). One unit of MS activity corresponds to $1 \mu \mathrm{mol}$ of malate formed per min at $30^{\circ} \mathrm{C}$.

MALDI-TOF mass spectrometry. For peptide mass fingerprinting, the protein band of interest (approximately 5 by 1.5 by $1 \mathrm{~mm}$ in size) was excised from colloidal Coomassie-stained gels with a scalpel and subjected to in-gel digestion with trypsin essentially as described previously (47). Briefly, gel pieces were washed twice for $10 \mathrm{~min}$ with $750 \mu \mathrm{l}$ of $0.1 \mathrm{M}$ ammonium bicarbonate in $30 \%$ ( $\mathrm{vol} / \mathrm{vol}$ ) acetonitrile. The destained and shrunken gel pieces were then vacuum dried for $20 \mathrm{~min}$ in a conventional vacuum centrifuge and subsequently rehydrated with $5 \mu \mathrm{l}$ of $3 \mathrm{mM}$ Tris- $\mathrm{HCl}(\mathrm{pH} 8.8)$ containing trypsin $(10 \mathrm{ng} / \mu \mathrm{l})$. After $20 \mathrm{~min}, 5 \mu \mathrm{l}$ of $3 \mathrm{mM}$ Tris- $\mathrm{HCl}$ ( $\mathrm{pH} 8.8$ ) without trypsin was added. Digestion was allowed to proceed overnight at room temperature. Peptides were then extracted by sequential addition of $12 \mu \mathrm{l}$ of water and $10 \mu \mathrm{l}$ of $0.1 \%$ (vol/vol) trifluoroacetic acid in $30 \%(\mathrm{vol} / \mathrm{vol})$ acetonitrile. A total of $0.5 \mu \mathrm{l}$ of the resulting peptide solution was mixed on a stainless steel sample plate with $0.5 \mu$ l of a saturated $\alpha$-cyano-4-hydroxy-trans cinnamic acid solution in $50 \%$ (vol/vol) acetonitrile$0.1 \%$ (vol/vol) trifluoroacetic acid. Close external calibration using calibration mixtures 1 and 2 of a Sequazyme peptide mass standard kit (Applied Biosystems, Weiterstadt, Germany) was performed for each sample. Samples were analyzed manually in positive-reflector mode with $20 \mathrm{kV}$ of accelerating voltage and $63 \%$ grid voltage; the delay time was set at $125 \mathrm{~ns}$. Data acquisition and analysis were performed using Voyager Control Panel software (version 5.0) and Voyager Data Explorer software (version 3.5) (Applied Biosystems). The generated mass lists and MS-Fit (6) were used to search the nonredundant National Center for Biotechnology Information (NCBI) database.

Computational analysis. Searches for protein domains were performed by using SMART (for "Simple Modular Architecture Research Tool") (48) and NPS@ (for "Network Protein Sequence Analysis") (7). Alignments were carried out by using BLAST (for "basic local alignment search tool") (1). The search within the genome of $C$. glutamicum for motifs with identity or similarity to the 13-bp motifs found in front of the pta-ack operon was performed with ERGO (Integrated Genomics, Chicago, Ill.).

\section{RESULTS}

Identification of cis-regulatory elements in the pta-ack and aceA/aceB promoter regions. The promoter region of the ptaack operon encoding the acetate-activating enzymes PTA and $\mathrm{AK}$ is shown in Fig. 1A. To study the relevance of the two promoters and of the two identical 13-bp motifs (M1 and M2; Fig. 1) for regulation of gene expression, we constructed a set of reporter gene fusions by cloning pta-ack promoter fragments of different lengths into the promoter test vector pET2. The promoter activity of these fragments was tested in the $C$. glutamicum WT strain (Fig. 1B) by measuring the specific activity of the reporter gene product CAT. The pRob19 fragment, covering the promoter region up to -320 bp upstream of 


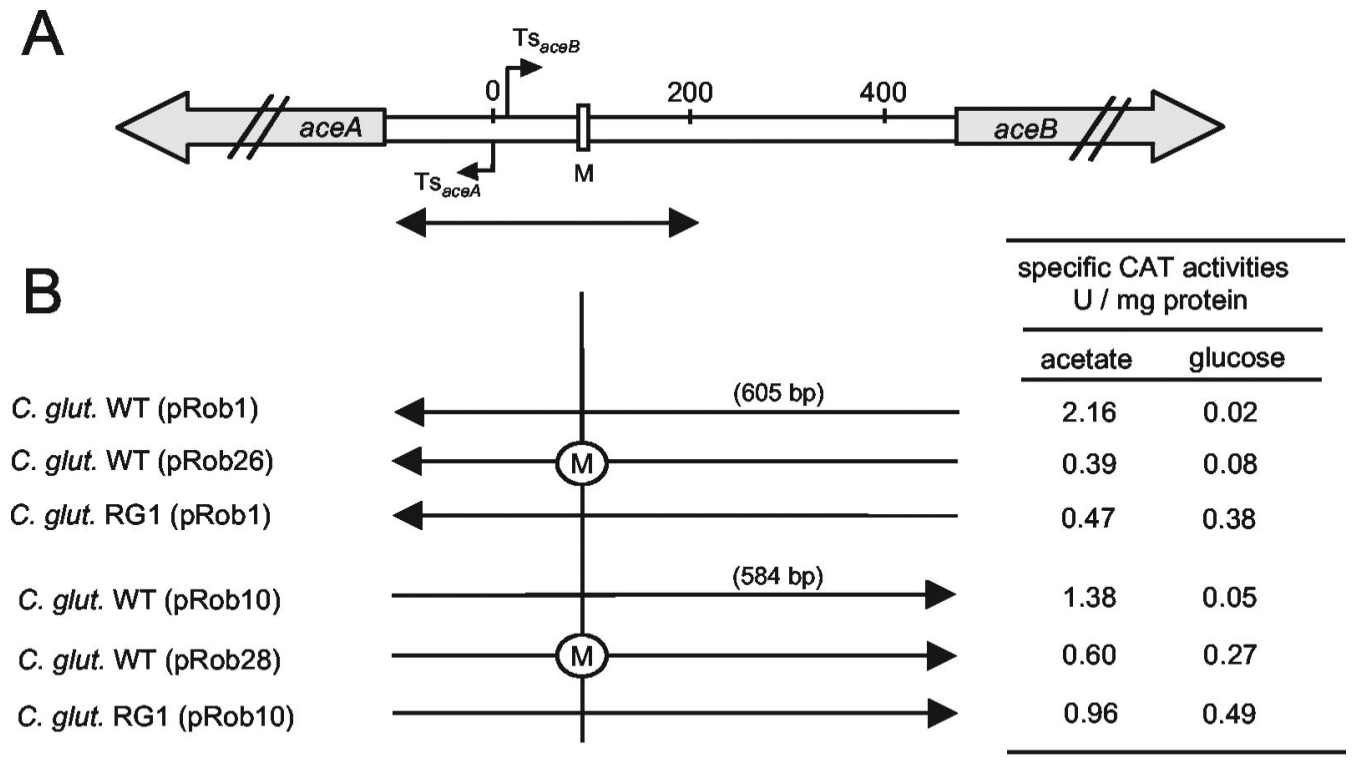

FIG. 2. Genomic locus of the $a c e A-a c e B$ intergenic promoter region (A) and specific promoter activities of $a c e A$ and $a c e B$ promoter fragments in cells of $C$. glutamicum WT and ramB mutant RG1 strains grown in minimal medium containing acetate or glucose as carbon and energy sources (B). (A) The ace $A$ and $a c e B$ transcriptional start sites are indicated as $\mathrm{Ts}_{\text {aceA }}$ and $\mathrm{Ts}_{\text {aceB }}$, respectively; the 13-bp motif is indicated as M. The promoter/operator probe used for the binding assays with purified His-tagged RamB protein is indicated by a double-headed arrow. (B) The promoter activity values represent specific activities of CAT determined using cell extracts of $C$. glutamicum (C. glut.) strains carrying the various promoter fragments (pRob11, pRob10, pRob26, pRob28) in plasmid pET2. The respective fragments are indicated by arrows. The circled "M"s indicate that the respective 13-bp motifs were destroyed by mutation. The promoter activity values given represent averages of at least three independent cultivations and two determinations per experiment.

the pta structural gene, led (in the presence of acetate in the growth medium) to an induction (or derepression) of CAT reporter gene expression by a factor of 3 . This is in agreement with the three- to sevenfold-higher expression of the pta-ack operon detected by Northern blotting and transcriptional fusion experiments (43) and indicates the presence of a cisregulatory element(s) in the pta-ack promoter region. In comparison to the results seen with the pRob19 fragment, the pRob22 fragment (lacking 228 bp that include the distal promoter with transcriptional start site Ts1 and the distal 13-bp motif M1; Fig. 1) led to a $25 \%$ lower promoter activity $(0.24$ versus $0.32 \mathrm{U} / \mathrm{mg}$ of protein) during growth on acetate and a four- to fivefold-higher promoter activity during growth on glucose $(0.47$ versus $0.10 \mathrm{U} / \mathrm{mg}$ of protein) (Fig. 1B). These observations suggest that (i) the promoter proximal to the pta-ack structural genes provides the major part of the activity under the tested conditions and (ii) the distal 13-bp motif M1 represents an important cis-regulatory element.

As the 13-bp motif occurs twice in the pta-ack promoter region, it was tempting to speculate that both motifs (M1 and M2) work together by binding a transacting regulatory protein and thus allowing transcriptional regulation of the pta-ack operon. To clarify the role of both motifs for the regulation of the operon, defined mutations were introduced into each motif alone and into both motifs, resulting in plasmids pRob30, pRob31, and pRob32, respectively. The native sequence of the motifs is AAAACTTTGCAAA; the sequence of the distal motif M1 was changed to AAAACGAGGCAAA (pRob31 and pRob32) (mutagenized nucleotides are indicated with double underlines), and the sequence of the proximal motif M2 was changed to AAAACGAGGCGAG (pRob30 and pRob32).
With all three constructs, the reporter enzyme activity in glucose-grown cells was significantly higher than that seen with pRob19; thus, the promoter activities of the fragments in pRob30, pRob31, and pRob32 were deregulated (Fig. 1B). This result strongly supports the hypothesis that both 13-bp motifs are involved in repression of the pck-ack operon during growth on glucose. It is worth mentioning that the fragments carrying mutations in the proximal motif M2 (pRob30 and pRob32) in acetate-grown cells showed about twofold-lower promoter activities than the fragments with the native motifs or with only the distal motif M1 mutagenized. These results might indicate that the intact region is required for maximal activity of the pta-ack promoters.

The intergenic promoter region of the ace $A /$ ace $B$ gene cluster encoding the glyoxylate cycle enzymes ICL and MS is shown in Fig. 2A. In proximity to the $a c e A$ and $a c e B$ transcriptional start sites, the region also contains a motif with internal dyad symmetry (AGAACTTTGCAAA) (M; Fig. 2A) which is identical to the 13-bp motifs in the pta-ack promoter region except for one nucleotide ( $G$ instead of $A$ ) at position 2. To study the relevance of this motif for regulation of ace $A$ and $a c e B$ expression, we constructed $c a t$ reporter gene fusions by cloning the ace $A / a c e B$ intergenic promoter region with the native motif and with a mutagenized motif (AGAACGAGGC $\mathrm{AAA}$ ) in both orientations into the promoter test vector $\mathrm{pET} 2$, resulting in plasmids pRob1 and pRob26 for testing the ace $A$ promoter and pRob10 and pRob28 for testing the $a c e B$ promoter, respectively. The promoter activity of these fragments was then tested by measuring the specific CAT activity in $C$. glutamicum WT cells grown on acetate and on glucose minimal medium (Fig. 2B). The pRob1 and pRob10 fragments (both 
with native 13-bp motifs) conferred about 100- and 40-foldhigher cat expression, respectively, when the cells were grown on acetate instead of glucose. This result is in agreement with the $a c e A$ and $a c e B$ expression ratios observed in previous studies (reviewed in reference 14) and indicates the presence of a cis-regulatory element(s) in the $a c e A / a c e B$ promoter region.

The use of the pRob26 and pRob28 fragments (both with mutagenized 13-bp motifs) still led to regulated promoter activity; however, the regulation was much weaker (i.e., only about fivefold-higher [ 0.39 versus $0.08 \mathrm{U} / \mathrm{mg}$ of protein] and twofold-higher [0.60 versus $0.27 \mathrm{U} / \mathrm{mg}$ of protein] cat expression, respectively, was seen when the cells were grown on acetate instead of glucose). Thus, the 13-bp motif is involved in the transcriptional regulation of the $a c e A$ and $a c e B$ genes, although the transcriptional regulation of both genes may be additionally mediated by another so-far-unknown cis-acting element(s). It is interesting that the promoter activities in acetate-grown cells of C. glutamicum (pRob26 and pRob28) were significantly (five- and twofold, respectively) lower than in the C. glutamicum strains carrying the respective constructs with the native promoter fragments (pRob1 and pRob10, respectively) (Fig. 2B). This result is similar to that obtained with motif M2 and the pta-ack promoter and indicates that an intact 13-bp motif is also essential for maximal activity of both the ace $A$ and $a c e B$ promoters.

Isolation and identification of the novel repressor protein RamB. Having gained evidence for the involvement of the 13-bp motifs M1 and M2 in the regulation of the pta-ack operon, we attempted to enrich a regulatory protein(s) binding specifically to the promoter/operator region by DNA affinity purification with magnetic streptavidin beads. A 221-bp biotinylated promoter/operator probe (positions -61 to $-282 \mathrm{bp}$ upstream of the pta start codon) comprising M1 and M2 (Fig. 1A) was linked to streptavidin-coated magnetic beads and incubated with crude extracts from $C$. glutamicum cells grown on minimal medium containing glucose or acetate. To remove non-specifically-bound proteins from the promoter/operator probe, we performed several low-salt $(100 \mathrm{mM} \mathrm{NaCl})$ washing steps with subsequent magnetic separation. We then eluted specifically bound proteins with a buffer containing $200 \mathrm{mM}$ $\mathrm{NaCl}$. In a parallel approach, a homologous probe (pta-mut) with mutagenized motifs was used as a control, allowing us to discriminate between specific and nonspecific protein-DNA interactions. The eluted fractions were analyzed by SDSPAGE.

As shown in Fig. 3, a single protein with a molecular mass of about $53 \mathrm{kDa}$ was highly enriched from crude extracts of $C$. glutamicum cells grown on glucose as well as from cells grown on acetate. The protein specifically bound to the promoter/ operator probe with the original motif (AAAACTTTGCAAA) but did not bind to the pta-mut probe in which both motifs were mutagenized (AAAACGAGGCAAA in M1 [mutagenized nucleotides are indicated with double underlines]; AAAACGAGGCGAG in M2). The protein band was isolated and subjected to MALDI-TOF mass spectrometry and peptide mass fingerprint analysis. Comparison of the results with data in the nonredundant NCBI database resulted in the identification of a $C$. glutamicum protein with the accession number NP_599617 (NCBI). The corresponding gene was sequenced in the course of the determination of the genome sequence of

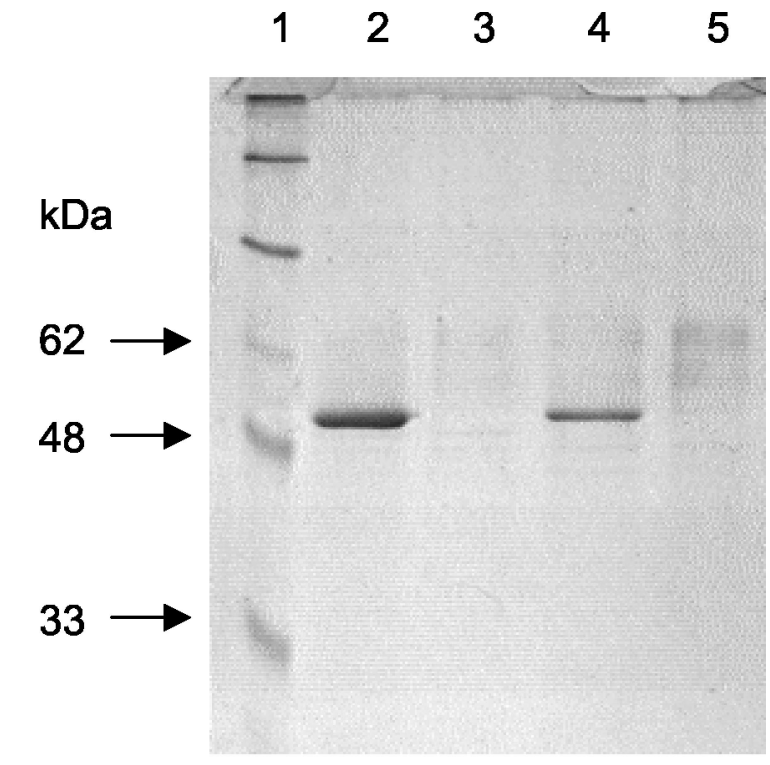

FIG. 3. SDS-PAGE of $C$. glutamicum proteins eluted from a DNA affinity chromatography experiment using the pta-ack promoter/operator as a probe and cell extracts from acetate-grown cells (lanes 2 and 3 ) and glucose-grown cells (lanes 4 and 5). In lanes 2 and 4, proteins were eluted from the promoter/operator probe with native 13-bp motifs, in lanes 3 and 5, proteins were eluted from the probe with mutagenized motifs. Lane 1, molecular mass marker.

C. glutamicum (NC_003450). It has a length of 1,410 bp and is preceded by a ribosomal binding site (GGAAAGA) and followed by a sequence resembling a Rho-independent transcriptional terminator centered $31 \mathrm{bp}$ downstream of the TAA stop codon $\left[\Delta \mathrm{G}\left(25^{\circ} \mathrm{C}\right)=-14.4 \mathrm{kcal} \mathrm{mol}^{-1}\right]$.

Probably due to the similarity of the deduced polypeptide to putative transcriptional regulators from different organisms (see Discussion), the gene product has been annotated as a "predicted transcriptional regulator." The deduced protein consists of 469 amino acids (aa) with a predicted molecular mass of $53.2 \mathrm{kDa}$, which corresponds well to the experimentally determined mass of the protein isolated by DNA affinity chromatography (Fig. 3). Using the method of Combet et al. (7), a putative HTH motif was identified at the $\mathrm{N}$ terminus (aa positions 14 to 35 ); therefore, the protein likely represents a transcriptional regulator. As the protein obviously controls expression of the pta-ack operon and (as shown below) also of the ICL and MS genes ace $A$ and $a c e B$, we designated it RamB (for "regulator of acetate metabolism B") and the corresponding gene $\mathrm{ram} B$.

Inspection of the C. glutamicum genomic locus of $\mathrm{ramB}$ revealed that it is located upstream of and in the orientation opposite to that of the genes coding for the succinate dehydrogenase subunits C/D, A, and B (NP_599618, NP_599619, and NP 599620; NCBI). Downstream of and in the orientation opposite to that of the $\operatorname{ramB}$ gene there is an open reading frame probably coding for an UDP-glucose pyrophosphorylase (NP_599615).

Binding of purified RamB protein to the pta-ack and aceA/ aceB promoter/operator regions. To prove the direct binding of the RamB protein to the pta-ack and aceA/aceB promoter/ operator regions, the protein was synthesized as a hexahistidyl 


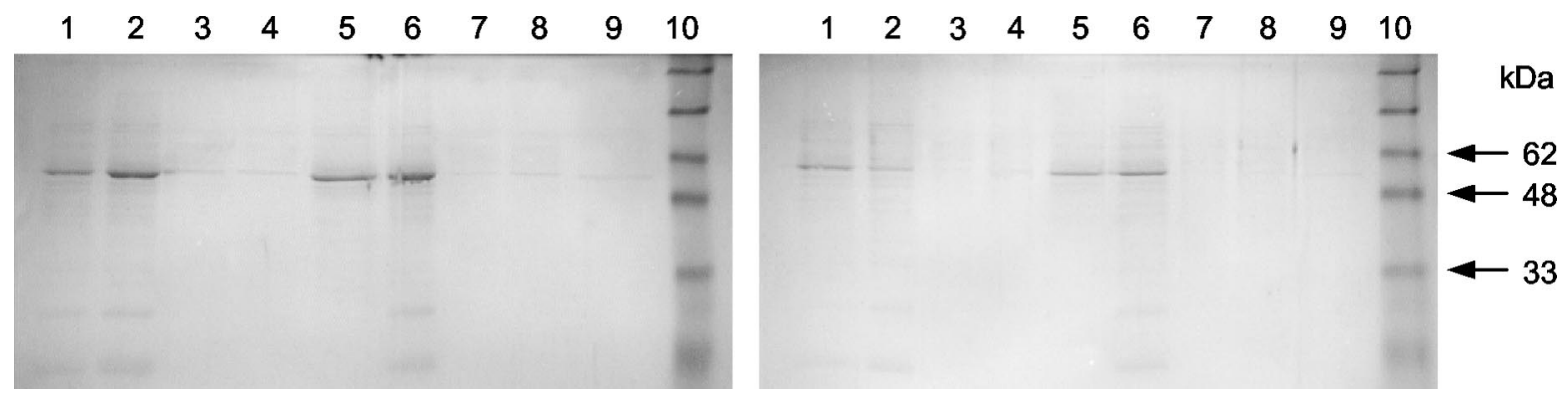

FIG. 4. SDS-PAGE of hexahistidyl-tagged RamB protein eluted from a DNA affinity chromatography experiment using the pta-ack promoter/ operator (left panel) or the $a c e A / a c e B$ promoter/operator (right panel) as a probe. Lane 1 represents the purified RamB fusion protein; lane 10 represents the molecular mass marker. Lanes $2,3,4$, and 5 contained aliquots of the fraction incubated with the coupled Dynabeads and the 100 and $200 \mathrm{mM}$ and $1 \mathrm{M} \mathrm{NaCl}$ elution fractions, respectively, from the beads with native promoter/operator regions. Lanes 6 to 9 represent the respective fractions from the beads with promoter/operator regions with mutagenized 13-bp motifs.

fusion protein in E. coli BL21 and purified by affinity chromatography. Purified His-tagged protein was incubated with streptavidin-coated magnetic beads coupled with either biotinlabeled pta-ack or biotin-labeled $a c e A / a c e B$ promoter/operator probe, respectively, and then eluted with buffer containing increasing concentrations of $\mathrm{NaCl}$. In a parallel approach, promoter/operator probes with mutagenized motifs were used. As shown by SDS-PAGE analysis of the various elution fractions (Fig. 4), the RamB protein bound to both native promoter/ operator probes and could be eluted after several low-salt washing steps (100 and $200 \mathrm{mM} \mathrm{NaCl}$ ) with $1 \mathrm{M} \mathrm{NaCl}$. In contrast, the RamB protein did not bind to the pta-ack and ace $A /$ ace $B$ promoter/operator probes with mutagenized motifs, as indicated by the fact that none of the washing and elution fractions contained the protein. These results show the direct binding of RamB to the pta-ack and aceA/aceB promoter/ operator regions and corroborate the significance of the 13-bp motifs for these interactions.

To test for acetyl-CoA as a negative effector for the binding of RamB, we performed the binding assays using the native pta-ack and aceA/aceB promoter/operator probes and Histagged RamB protein in the presence of $0.5 \mathrm{mM}$ acetyl-CoA. The binding behavior of RamB in these assays was completely identical to that observed without acetyl-CoA (data not shown), indicating that the presence of this compound has no negative effect.

Inactivation of ramB in C. glutamicum and effect on growth. To functionally analyze the RamB protein of $C$. glutamicum, we constructed the $\operatorname{ramB}$ mutant $C$. glutamicum RG1. In this mutant, the 5' coding region of $\mathrm{ramB}$ was shortened in frame by $776 \mathrm{bp}$, thereby creating a 648-bp open reading frame encoding a drastically truncated RamB protein. The success of the deletion within the $\operatorname{ramB}$ gene was confirmed by PCR and by Southern blot analysis (data not shown).

C. glutamicum strain RG1 and the parental WT strain were tested for growth on different media. The mutant showed a reduced growth rate compared to the WT $\left(\mu=0.35 \mathrm{~h}^{-1}\right.$ versus $\mu=0.40 \mathrm{~h}^{-1}$ ) during exponential growth on minimal medium containing glucose, it entered the stationary phase earlier than the WT, and the final $\mathrm{OD}_{600}$ value was lower (14 to 15 versus 20 to 21 ). Growth of the $\operatorname{ramB}$ mutant RG1 on minimal medium containing acetate was slightly impaired, with lower growth rates $\left(\mu=0.27 \mathrm{~h}^{-1}\right.$ versus $\left.\mu=0.30 \mathrm{~h}^{-1}\right)$ and a lower final $\mathrm{OD}_{600}$ (6 to 7 versus 8 to 9$)$. The altered growth characteristics of $C$. glutamicum RG1 suggest a direct or indirect effect of the presence of RamB protein on metabolic pathways which are relevant both for glucose and acetate catabolism.

Effect of $\operatorname{ramB}$ inactivation on specific PTA and AK activities and pta-ack promoter activity. To test for an involvement of RamB in the expression control of the pta-ack operon, the respective specific PTA and AK activities were measured in crude extracts of $C$. glutamicum strain RG1 and the C. glutamicum WT strain after growth of the cells on acetate and glucose minimal medium (Fig. 5). Whereas the specific activities of PTA and AK in C. glutamicum WT were four- to fivefold higher during growth on acetate than during growth on glu-
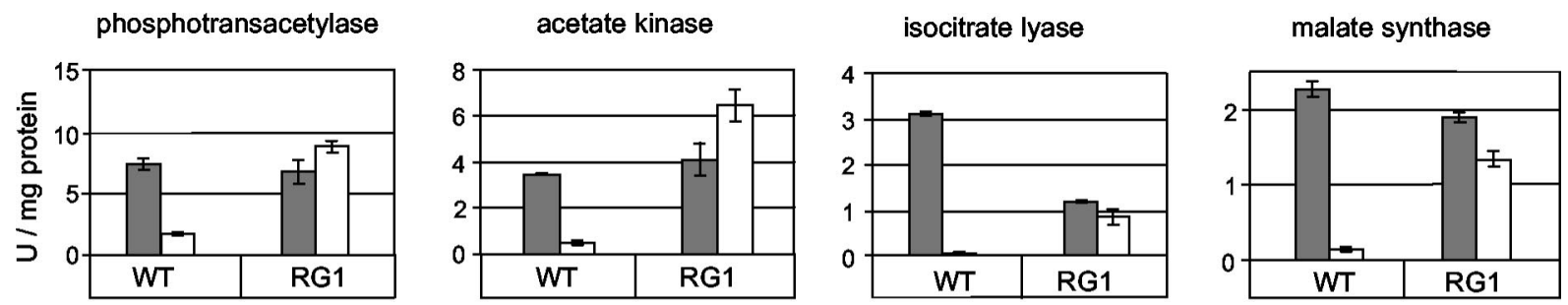

Acetate $\square$ Glucose

FIG. 5. Specific activities of PTA, AK, ICL, and MS of C. glutamicum WT and ramB mutant $C$. glutamicum RG1 strains in cell extracts of cells grown in minimal medium containing acetate or glucose. The activity values represent means \pm standard deviations for at least three independent cultivations and two determinations per experiment. 
cose, C. glutamicum RG1 showed high-level specific activities of both enzymes irrespective of the carbon source. The specific PTA and AK activities of the mutant grown on glucose medium surpassed even those of cells grown on acetate (Fig. 5). These results suggest that $\mathrm{RamB}$ is a transcriptional repressor of the C. glutamicum pta-ack operon, repressing its expression during growth on glucose and therefore leading to low PTA and $\mathrm{AK}$ activities under these conditions. This repression obviously is released when acetate is available as a carbon source, leading to elevated PTA and AK enzyme levels and therefore to high-level specific activities. To test this hypothesis, promoter fusion assays were carried out. The promoter activity of the pta-ack promoter-reporter gene fusion pRob19 (see above) in the $C$. glutamicum WT was compared to the activity of the same construct in the $\operatorname{ramB}$ mutant RG1 (Fig. 1B, bottom line). In contrast to the results seen with the $C$. glutamicum WT (pRob19), strain RG1 (pRob19) showed a completely deregulated promoter activity during growth on glucose, with activity even higher than that seen during growth on acetate (Fig. 1). From these results it follows that RamB represses transcription of the C. glutamicum pta-ack operon when the cells are grown on glucose.

Effect of ramB inactivation on specific ICL and MS activities and on ace $A$ and $\boldsymbol{a c e B}$ promoter activity. To test whether the $\operatorname{ram} B$ deletion also affects the expression of the $a c e A$ and $a c e B$ genes, we measured the specific ICL and MS activities in crude extracts of the C. glutamicum WT and $\operatorname{ramB}$ mutant $C$. glutamicum RG1 strains after growth on acetate and glucose minimal media (Fig. 5). Whereas the specific ICL and MS activities in WT cells were much lower when the cells were grown on glucose than when they were grown on acetate, $C$. glutamicum RG1 cells showed only slightly lower-level specific ICL and MS activities when grown on glucose. When C. glutamicum RG1 cells were grown in acetate medium, however, the specific enzyme activities (especially that of ICL) were lower than those reached by the WT strain (Fig. 5). These data suggest that expression of the $C$. glutamicum ace $A$ and ace $B$ genes is also repressed by RamB during growth on glucose and that this repression is released when acetate is the carbon and energy source.

The influence of the $\operatorname{ram} B$ deletion on the transcription of the ICL and MS genes ( $a c e A$ and $a c e B$, respectively) was tested in another set of promoter fusion experiments (Fig. 2B). The promoter activities of the $a c e A / a c e B$ intergenic region (cloned in either orientation in front of the CAT reporter gene) were measured in the ramB mutant $C$. glutamicum RG1 strain and compared to the respective promoter activities in the parental WT strain. When grown in glucose medium, strains RG1 (pRob1) and RG1 (pRob10) showed deregulated aceA/aceB promoter activities, with 19-fold (aceA)- and 10-fold (aceB)higher-level activities compared to the results seen with the respective WT strains carrying pRob1 and pRob10 (Fig. 2B). These results correspond well to the increased specific ICL and MS activities of the mutant on glucose (Fig. 5). When cells were grown on acetate, the levels of $a c e A / a c e B$ promoter activities in C. glutamicum RG1 (pRob1) and RG1 (pRob10) were lower than those seen with $C$. glutamicum WT (pRob1) and WT (pRob10), respectively. These results also correspond to the lower ICL and MS activities of acetate-grown cells of strain RG1 compared to those of acetate-grown cells of the
WT strain (Fig. 5). Taken together, the results indicate on the one hand that RamB represses ace $A$ and $a c e B$ in the presence of glucose in the growth medium. On the other hand, they suggest that in contrast to the situation with the pta-ack operon, RamB is necessary for full $a c e A$ and $a c e B$ promoter activity in the presence of acetate in the growth medium.

\section{DISCUSSION}

The acetate-activating enzymes AK and PTA and the glyoxylate cycle enzymes ICL and MS of $C$. glutamicum are coordinately and specifically up-regulated by the presence of acetate in the growth medium, and this regulation mainly occurs by induction and/or derepression of the respective genes (see the introduction and references 43 and 60). Although much progress in the elucidation of the acetate metabolism of $C$. glutamicum has been made during the last years (reviewed in reference 14), however, neither the operator sequences nor the regulatory protein(s) involved in the transcriptional regulation of the four enzymes has been determined so far; thus, the molecular regulatory mechanism(s) of the acetate metabolism in this organism has not yet been understood. In other bacteria utilizing acetate for growth, the enzymes involved in acetate metabolism are also regulated at the transcriptional level. In Bacillus subtilis, the ack and pta genes are monocistronic genes; both are under the transcriptional control of the catabolite control protein CcpA $(16,40,51)$, a member of the LacI-GalR family of bacterial regulatory proteins and a key regulator of many central and specific catabolic pathways in B. subtilis (3, $22,23,34,52,62)$. In contrast to the situation in $C$. glutamicum, however, the $B$. subtilis ack and pta genes are induced in the presence of glucose. It has been suggested that in this organism, AK and PTA are not required for utilization of acetate but are required for its formation during growth on glucose $(3,16)$. Obviously, B. subtilis mainly uses the acetyl-CoA synthetase reaction for acetate activation instead of the AK/PTA pathway (17). Acetyl-CoA synthetase has been shown to be essential for growth of $B$. subtilis on acetate, and the respective $a \operatorname{cs} A$ gene is repressed in the presence of excess glucose in the growth medium $(3,17,18)$. This repression is also mediated by the CcpA protein at a cis-acting site called cre (for "carbon repression element") which is a palindromic 14-bp sequence and has been found in a large variety of genes controlled by CcpA (3, 27, 59). In E. coli, the ack and pta genes (organized as an ack-pta operon) are slightly induced under anaerobiosis and starvation conditions but not by acetate in the growth medium $(4,36)$. In fact, an approximately twofold down-regulation in the presence of acetate has been reported previously $(37,38)$. This (and the fact that $E$. coli possesses an acetate-inducible acetyl-CoA synthetase) $(4,37)$ indicates that in this organism also, the acetyl-CoA synthetase reaction plays the major role for acetate activation. The induction of the E. coli acetyl-CoA synthetase gene acs seems to be very complex and depends on the carbon regulator cyclic AMP receptor protein (CRP), the oxygen regulator FNR, and the glyoxylate shunt repressor IclR and its activator FadR (30). The IclR protein is also the repressor of the E. coli ICL and MS genes aceA and aceB (53, 61 ), which are organized as an operon together with the aceK gene encoding the isocitrate dehydrogenase kinase-phosphatase (5). Additionally, the $a c e B$-aceA-aceK operon is positively 
controlled by the pleiotropic transcriptional regulator Cra and by the integration host factor $(8,19)$. However, for $C$. glutamicum there is no experimental evidence so far for the presence of functional homologues of CRP, FNR, IclR, Cra, integration host factor, or CcpA and thus none for the presence of the regulatory devices known to regulate the expression of genes involved in acetate metabolism in other bacteria. Instead, the data presented here give clear evidence for a novel regulatory protein, RamB, which in C. glutamicum is responsible for expression control of the AK, PTA, ICL, and MS genes and, thus, for the proper adaptation of this organism to acetate as carbon and energy source.

According to the nucleotide sequence, the RamB protein consists of 469 aa with a putative HTH motif at the N terminus. BLAST databank analysis revealed significant levels of identity or similarity of RamB to putative regulatory proteins from other bacteria: $91 \%$ identity to a putative transcriptional regulator from $C$. efficiens YS-314 (NCBI accession no. BAC17195) and $56 \%$ identity to both the hypothetical protein Rv0465c from Mycobacterium tuberculosis H37Rv (accession no. CAA17420) and a probable transcriptional regulatory protein from M. bovis subsp. bovis AF2122/97 (accession no. CAD93337). Furthermore, the deduced RamB protein of $C$. glutamicum shows significant $(>40 \%$ ) levels of identity to hypothetical proteins from Streptomyces avermitilis MA-4680 (accession no. BAC69753), S. coelicolor A3 (2) (accession no. CAC44331), and Rhodospirillum rubrum (accession no. ZP_00016372). None of the above-listed proteins has been functionally analyzed so far. SMART analysis (48) of all the proteins (including RamB) revealed that they carry an N-terminal domain with significant similarity to the so-called HTHXRE DNA-binding domain (accession no. SM00530). This domain is a characteristic element of the XRE family-like proteins, a large family of DNA-binding proteins found in a variety of bacteria (48). Since most of the XRE family proteins are hypothetical proteins, no prediction with respect to a general function can be made for the members of this protein family. In accordance with the HTH position-function relationship (39), however, the C. glutamicum RamB protein with its HTH motif at its $\mathrm{N}$ terminus likely represents a repressor protein. This assumption has been verified here by functional analysis of purified RamB protein, by characterization of the ramB mutant $C$. glutamicum RG1, and by transcriptional fusion experiments.

Analysis of the ramB mutant C. glutamicum RG1 demonstrated that RamB negatively affects the specific activity of AK, PTA, ICL, and MS when the cells are grown on glucose. Together with the finding that RamB specifically binds to the promoter/operator regions of the respective genes and that regulation takes place at the transcriptional level, the data clearly indicate a repressor function of RamB in glucose-grown cells. Although our data as well as previous results $(14,60)$ strongly suggest a tightly linked transcriptional control of both pta-ack and the $a c e A / a c e B$ gene clusters, the effect of $\operatorname{ramB}$ inactivation on the pta-ack operon is slightly different from that on ace $A$ and $a c e B$. Whereas pta-ack was completely deregulated in RG1 cells grown on glucose medium, there was still some residual regulation of the ace $A$ and $a c e B$ genes. Moreover, the level of expression of ace $A$ and $a c e B$ but not of the pta-ack operon was significantly lower in the $\operatorname{ramB}$ mutant than in the WT when the cells were grown on acetate. These differences may partly be caused by different affinities of the RamB protein to the promoter/operator regions, due to the different number and/or locations of the 13-bp motifs, and/or to different nucleotide sequences in the neighborhood of the binding site(s). However, the data suggest the involvement of an additional regulatory factor or protein (aside from RamB) in expression control of $a c e A$ and $a c e B$. This factor or protein may directly or indirectly modulate the function of the RamB protein in the context of the ace $A / a c e B$ promoter/operator region and also may act independently, as an additional regulator, on ace $A$ and $a c e B$ expression. The involvement of a repressor as well as an activator in the transcriptional control of the C. glutamicum enzymes of acetate metabolism has recently been proposed on the basis of cosubstrate experiments and the isolation and enzymatic analysis of an undefined $C$. glutamicum mutant (TMG25) which is obviously defective in the repression mechanism (14). The identification and characterization of the proposed activator and the analysis of its role in the acetate metabolism of $C$. glutamicum are among the challenges for future research.

The RamB protein was isolated from acetate- as well as from glucose-grown cells of $C$. glutamicum; thus, the protein is present under both growth conditions. This indicates that RamB is functionally controlled by an effector molecule which is specific for one or the other of the growth conditions. On the basis of analysis of C. glutamicum mutants defective (i.e., either AK or PTA deficient) in the acetate activation pathway and on a correlation between a high intracellular acetyl-CoA concentration with high-level specific AK, PTA, ICL, and MS activities, acetyl-CoA itself or a derivative thereof has been proposed to be the physiological trigger of the transcriptional regulation of the four enzymes (60). The results of our binding assays performed in the presence or absence of acetyl-CoA indicate that acetyl-CoA itself does not alter the binding behavior of RamB and, thus, that acetyl-CoA is not the physiological trigger of the transcriptional regulation brought about by the presence of RamB protein. However, whether a derivative of acetyl-CoA binds to RamB and/or affects the DNA binding activity of the RamB protein is not yet known and has to be elucidated.

The RamB protein was isolated from cell extracts of $C$. glutamicum by DNA affinity chromatography. This method previously has been successfully applied for the isolation of DNA-binding proteins, e.g., the yeast transcription factor $\tau$ (13), the Staphylococcus aureus SarH1 global regulator of virulence gene expression (54), and (very recently) the putative transcriptional repressor McbR from C. glutamicum (44). McbR has been shown to be involved in the regulation of the metabolic network directing the synthesis of L-methionine in C. glutamicum (44). Using cell extracts from C. glutamicum for the DNA affinity chromatography, the RamB protein was liberated from the pta-ack promoter/operator probe under relatively mild conditions (elution with $200 \mathrm{mM} \mathrm{NaCl}$ ) and therefore was apparently not very tightly bound. This result opened the possibility that RamB indirectly bound to the probe via another DNA-binding protein present in the cell extract. However, purified RamB protein tightly bound to the native pta-ack and ace $A /$ ace $B$ promoter/operator regions and did not bind to identical probes with mutagenized 13-bp motif(s). This result 
TABLE 2. Proteins encoded by genes preceded by sequences with identity or similarity with the 13-bp motifs found in the promoter/operator region of the pta-ack operon and locations of these sequences

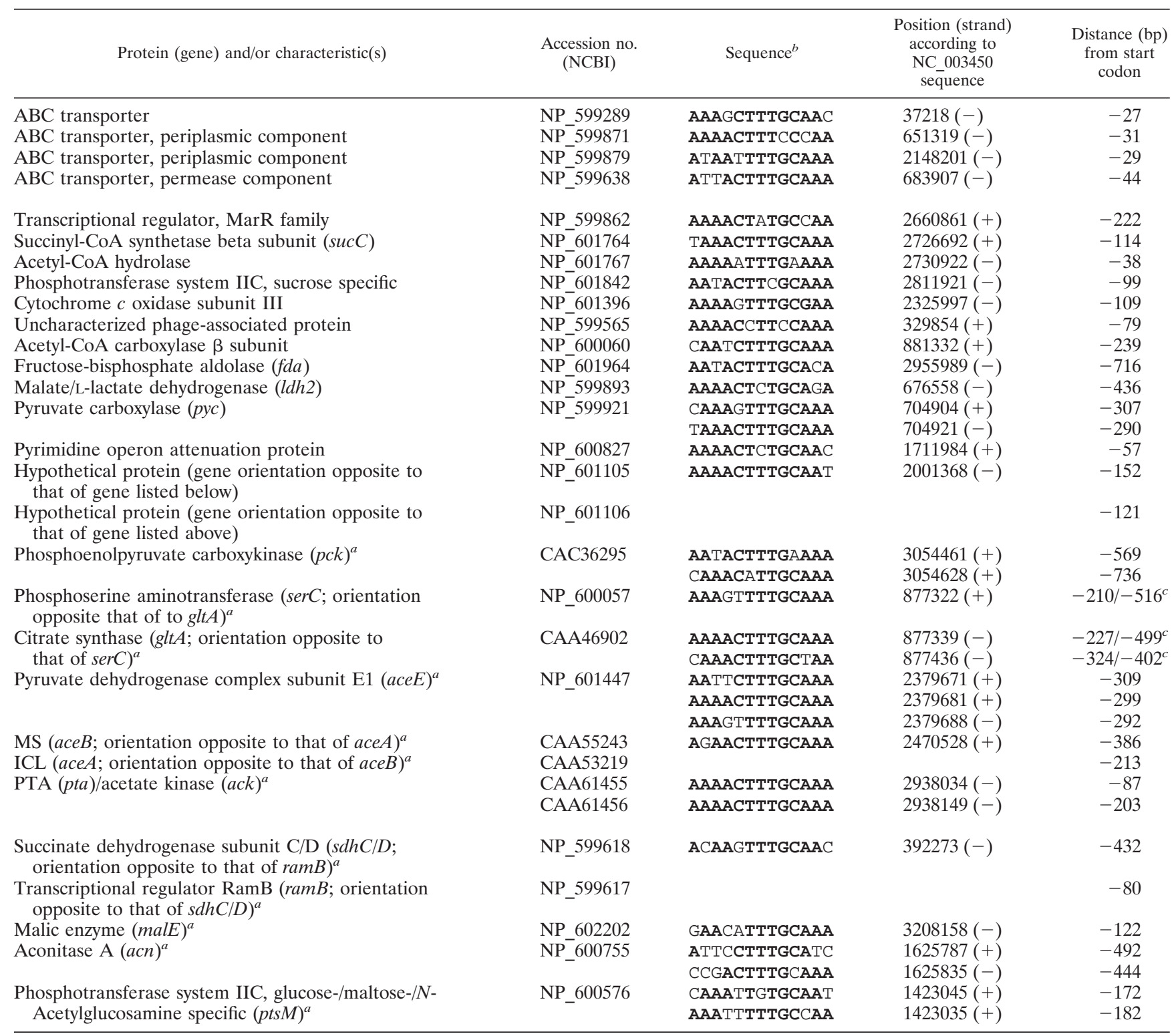

\footnotetext{
${ }^{a}$ Proteins encoded by genes of the acetate stimulon.

${ }^{b}$ Matches with respect to the 13-bp motifs of the pta-ack promoter/operator are indicated with boldface characters.

${ }^{c}$ The first number refers to the distance to $\operatorname{ser} C$; the second refers to the distance to glt $A$.
}

shows the high-level specificity of the RamB binding for the respective DNA regions and (in particular) for the motif.

Recent genome-wide and comparative expression analyses with $C$. glutamicum grown on glucose and on acetate revealed that in addition to the pta-ack operon and the ace $A$ and ace $B$ genes, a variety of other genes are obviously under transcriptional control in response to the presence or absence of acetate in the growth medium $(14,21,35)$. These genes (thus belonging to the acetate stimulon) include those for some of the enzymes of the tricarboxylic acid cycle (citrate synthase, aconitase, succinate dehydrogenase subunits $\mathrm{A}, \mathrm{B}$, and $\mathrm{C} / \mathrm{D}$, and fumarase) and for some of the enzymes involved in sugar metabolism (glucose-specific phosphotransferase system en- zyme II, glucose-6-phosphate dehydrogenase, transaldolase, transketolase, pyruvate kinase, and pyruvate dehydrogenase complex E1 subunit). The mRNA levels of the former group of genes (tricarboxylic acid cycle) were higher and those of the latter group (sugar metabolism) were lower in acetate-grown cells. The obvious regulation of these and other genes in response to the presence or absence of acetate prompted us to analyze the genome sequence of $C$. glutamicum for DNA elements with high levels of identity to the 13-bp RamB binding motifs found in the pta-ack promoter/operator region. Computational search allowing two mismatches within the whole 13-bp sequence revealed 28 sites in or around the promoter regions of structural genes (Table 2). Two or even three motifs 
were located in front of the genes encoding pyruvate carboxylase, PEP carboxykinase, citrate synthase, subunit E1 of the pyruvate dehydrogenase complex, and PTA-AK. Out of the 28 sites, 11 were found in the upstream regions of genes belonging to the acetate stimulon. Specific analysis of the promoter regions of other genes belonging to the acetate stimulon revealed that less-conserved (up to five mismatches) forms of the 13-bp motif are present in the upstream regions of five further genes (Table 2). In accordance with all these findings, it might be speculated that the 13-bp motif identified in this study has broader significance as a cis-active determinant in a global regulatory system of $C$. glutamicum. However, this hypothesis has to be addressed in future studies.

Finally, it is worth discussing that we found RamB to be $56 \%$ identical to the hypothetical protein Rv0465c of M. tuberculosis, which is closely related to $C$. glutamicum. Inspection of the M. tuberculosis genome (NC_000962) revealed the Rv0465c gene to be located $1.2 \mathrm{~kb}$ upstream of the ace $A$ gene. This gene codes for an ICL which is $79 \%$ identical to the respective enzyme of $C$. glutamicum (25). The $M$. tuberculosis ace $A$ is separated from the Rv0465c gene by another gene encoding a hypothetical protein (Rv0466). Inspection of the promoter region of the $M$. tuberculosis ace $A$ gene revealed a 13-bp DNA element (CAAAATTTGCAAA) very similar to the RamB binding motifs found in the pta-ack and aceA/aceB promoter/ operator regions of $C$. glutamicum. The 13-bp element of $M$. tuberculosis is located $167 \mathrm{bp}$ from the ace $A$ translational initiation site and differs from the $C$. glutamicum motifs at only two (pta-ack motifs) or three (aceA/aceB motif) positions. Together with the observation that the ICL content in $M$. tuberculosis is higher in cells grown on acetate than in cells grown on glucose (25), our findings may indicate that the M. tuberculosis ace $A$ gene is transcriptionally regulated in a manner similar to that described here for the respective $C$. glutamicum gene. This is especially interesting in view of the fact that the ICL plays a pivotal role in the persistence of $M$. tuberculosis in macrophages and mice and, thus, in the pathology of chronic tuberculosis $(26,33)$. Accordingly, it might well be that the elucidation of the $M$. tuberculosis ace $A$ regulation has important implications for the understanding of mycobacterial persistence and perhaps also for the treatment of tuberculosis.

\section{ACKNOWLEDGMENTS}

We thank Marcella Eikmanns for critically reading the manuscript and Daniel Rey for technical advice with DNA affinity chromatography.

R. Gerstmeir obtained a fellowship from the Landesgraduiertenförderung of Baden Württemberg. The support of the BMBF (grant 031U113D/213D; Genome research on bacteria relevant for agriculture, environment and biotechnology) and Degussa is gratefully acknowledged.

\section{REFERENCES}

1. Altschul, S. F., W. Gish, W. Miller, E. W. Myers, and D. J. Lipmann. 1990 Basic local alignment search tool. J. Mol. Biol. 215:403-410.

2. Birnboim, H. C. 1983 . A rapid alkaline extraction method for the isolation of plasmid DNA. Methods Enzymol. 100:243-255.

3. Blencke, H.-M., G. Homuth, H. Ludwig, U. Mäder, M. Hecker, and J. Stülke. 2003. Transcriptional profiling of gene expression in response to glucose in Bacillus subtilis: regulation of the central metabolic pathways. Metab. Eng. 5:133-149.

4. Brown, T. D. K., M. C. Jones-Mortimer, and H. L. Kornberg. 1977. The enzymatic interconversion of acetate and acetyl-coenzyme A in Escherichia coli. J. Gen. Microbiol. 102:327-336.
5. Chung, T., D. J. Klumpp, and D. C. LaPorte. 1988. Glyoxylate bypass operon of Escherichia coli: cloning and determination of the functional map. J. Bacteriol. 170:386-392.

6. Clauser, K. R., P. Baker, and A. L. Burlingame. 1999. Role of accurate mass measurement $(+/-10 \mathrm{ppm})$ in protein identification strategies employing MS or MS/MS and database searching. Anal. Chem. 71:2871-2882.

7. Combet, C., C. Blanchet, C. Geourjon, and G. Deléage. 2000. NPS@: network protein sequence analysis. Trends Biochem. Sci. 25:147-150.

8. Cortay, J. C., D. Negre, M. Scarabel, T. M. Ramseier, N. B. Vartak, J. Reizer, M. H. Saier, Jr., and A. J. Cozzone. 1994. In vitro asymmetric binding of the pleiotropic regulatory protein, FruR, to the ace operator controlling glyoxylate shunt enzyme synthesis. J. Biol. Chem. 269:14885-14891.

9. Dixon, G. H., and H. L. Kornberg. 1959. Assay methods for key enzymes of the glyoxylate cycle. Biochem. J. 72:3P.

10. Dubendorff, J. W., and F. W. Studier. 1991. Controlling basal expression in an inducible $\mathrm{T} 7$ expression system by blocking the target $\mathrm{T} 7$ promoter with lac repressor. J. Mol. Biol. 219:45-59.

11. Eikmanns, B. J., M. Metzger, D. J. Reinscheid, and H. Sahm. 1991. Amplification of three threonine biosynthesis genes in Corynebacterium glutamicum and its influence on carbon flux in different strains. Appl. Microbiol. Biotechnol. 102:93-98.

12. Eikmanns, B. J., N. Thum-Schmitz, L. Eggeling, K. Lüdtke, and H. Sahm. 1994. Nucleotide sequence, expression and transcriptional analysis of the Corynebacterium glutamicum gltA gene encoding citrate synthase. Microbiology 140:1817-1828.

13. Gabrielsen, O. S., E. Hornes, L. Korsnes, A. Ruet, and T. B. Oyen. 1989. Magnetic DNA affinity purification of yeast transcription factor $\tau$-a new purification principle for the ultrarapid isolation of near homogeneous factor. Nucleic Acids Res. 17:6253-6267.

14. Gerstmeir, R., V. F. Wendisch, S. Schnicke, H. Ruan, M. Farwick, D. Reinscheid, and B. J. Eikmanns. 2003. Acetate metabolism and its regulation in Corynebacterium glutamicum. J. Biotechnol. 104:99-122.

15. Gornall, A. G., C. J. Bardawill, and M. M. David. 1949. Determination of serum proteins by means of the biuret reaction. J. Biol. Chem. 177:751-766

16. Grundy, F., D. A. Waters, S. H. Allen, and T. M. Henkin. 1993. Regulation of the Bacillus subtilis acetate kinase gene by CcpA. J. Bacteriol. 175:73487355 .

17. Grundy, F., D. A. Waters, T. Y. Takova, and T. M. Henkin. 1993b. Identification of genes involved in utilization of acetate and acetoin in Bacillus subtilis. Mol. Microbiol. 10:259-271.

18. Grundy, F., A. J. Turinsky, and T. Henkin. 1994. Catabolite regulation of Bacillus subtilis acetate and acetoin utilization genes by CcpA. J. Bacteriol. 176:4527-4533.

19. Gui, L., A. Sunnarborg, B. Pan, and D. C. LaPorte. 1996. Autoregulation of $i c l R$, the gene encoding the repressor of the glyoxylate bypass operon. J. Bacteriol. 178:321-324.

20. Hanahan, D. 1985. Studies on transformation of Escherichia coli with plasmids. J. Mol. Biol. 166:557-580.

21. Hayashi, M., H. Mizogushi, N. Shiraishi, M. Obayashi, S. Nakagawa, J. Imai, S. Watanabe, T. Ota, and M. Ikeda. 2002. Transcriptome analysis of acetate metabolism in Corynebacterium glutamicum using a newly developed metabolic array. Biosci. Biotechnol. Biochem. 66:1337-1344.

22. Henkin, T. M. 1996. The role of the CcpA transcriptional regulator in carbon metabolism in Bacillus subtilis. FEMS Microbiol. Lett. 135:9-15.

23. Henkin, T. M., F. J. Grundy, W. L. Nicholson, and G. H. Chambliss. 1991. Catabolite repression of alpha-amylase gene expression in Bacillus subtilis involves a trans-acting gene product homologous to the Escherichia coli Lacl and GalR repressors. Mol. Microbiol. 5:575-584.

24. Ho, S. N., H. D. Hunt, R. M. Morton, J. K. Pullen, and L. R. Pease. 1989. Site-directed mutagenesis by overlap extension using the polymerase chain reaction. Gene 77:51-59.

25. Höner zu Bentrup, K., A. Miczak, D. L. Swenson, and D. G. Russell. 1999. Characterization of activity and expression of isocitrate lyase in Mycobacte rium avium and Mycobacterium tuberculosis. J. Bacteriol. 181:7161-7167.

26. Höner zu Bentrup, K., and D. G. Russell. 2001. Mycobacterial persistence: adaptation to a changing environment. Trends Microbiol. 9:597-605.

27. Hueck, C. J., W. Hillen, and M. H. Saier, Jr. 1994. Analysis of cis-active sequence mediating catabolite repression in gram-positive bacteria. Res. Microbiol. 145:503-518.

28. Inoue, H., H. Nojima, and H. Okayama. 1990. High efficiency transformation of Escherichia coli with plasmids. Gene 96:23-28.

29. Kinoshita, S., and K. Tanaka. 1972. Glutamic acid, p. 263-324. In K. Yamada (ed.), The microbial production of amino acids. John Wiley, New York, N.Y.

30. Kumari, S., C. M. Beatty, D. F. Browning, S. J. Busby, E. J. Simmel, G. Hovel-Miner, and A. J. Wolfe. 2000. Regulation of acetyl coenzyme A synthetase in Escherichia coli. J. Bacteriol. 182:4173-4179.

31. Laemmli, U. K. 1970. Cleavage of structural proteins during the assembly of the head of bacteriophage T4. Nature 227:680-685.

32. Liebl, W. 1991. The genus Corynebacterium-nonmedical, p. 1157-1171. In A. Balows, H. G. Trüper, M. Dworkin, W. Harder, and K. H. Schleifer (ed.), The procaryotes, vol. 2. Springer, New York, N.Y. 
33. McKinney, J. D., K. Höner zu Bentrup, E. J. Munoz-Elias, A. Miczak, B. Chen, W. T. Chan, D. Swenson, J. C. Sacchetti, W. R. Jacobs, Jr., and D. G. Russell. 2000. Persistence of Mycobacterium tuberculosis in macrophages and mice requires the glyoxylate shunt enzyme isocitrate lyase. Nature 406:683685.

34. Moreno, M. S., B. L. Schneider, R. R. Maile, W. Weyler, and M. H. Saier, Jr 2001. Catabolite repression mediated by the CcpA protein in Bacillus subtilis: novel modes of regulation revealed by whole-genome analyses. Mol. Microbiol. 39:1366-1381.

35. Muffler, A., S. Bettermann, M. Haushalter, A. Hörlein, U. Neveling, M. Schramm, and O. Sorgenfrei. 2002. Genome-wide transcription profiling of Corynebacterium glutamicum after heat shock and during growth on acetate and glucose. J. Biotechnol. 98:255-268.

36. Nyström, T. 1994. The glucose-starvation stimulon of Escherichia coli: in duced and repressed synthesis of enzymes of central metabolic pathways and role of acetyl phosphate in gene expression and starvation survival. Mol Microbiol. 12:833-843.

37. Oh, M. K., L. Rohlin, K. C. Kao, and J. C. Liao. 2002. Global expression profiling of acetate-grown Escherichia coli. J. Biol. Chem. 277:13175-13183.

38. Oh, M. K., and J. C. Liao. 2000. Gene expression profiling by DNA microarrays and metabolic fluxes in Escherichia coli. Biotechnol. Prog. 16:278-286.

39. Perez-Rueda, E., J. D. Gralla, and J. Collado-Vides. 1998. Genomic position analyses and the transcription machinery. J. Mol. Biol. 275:165-170.

40. Presecan-Siedel, E., A. Galinier, R. Longin, J. Deutscher, A. Danchin, P. Glaser, and I. Martin-Verstraete. 1999. Catabolite regulation of the pta gene as part of carbon flow pathways in Bacillus subtilis. J. Bacteriol. 181:68896897.

41. Reinscheid, D. J., B. J. Eikmanns, and H. Sahm. 1994. Characterization of the isocitrate lyase gene from Corynebacterium glutamicum and biochemical analysis of the enzyme. J. Bacteriol. 176:3474-3483.

42. Reinscheid, D. J., B. J. Eikmanns, and H. Sahm. 1994b. Malate synthase from Corynebacterium glutamicum: sequence analysis of the gene and biochemical characterization of the enzyme. Microbiology 140:3099-3108.

43. Reinscheid, D. J., S. Schnicke. D. Rittmann, U. Zahnow, H. Sahm, and B. J. Eikmanns. 1999. Cloning, sequence analysis, expression and inactivation of the Corynebacterium glutamicum pta-ack operon encoding phosphotransacetylase and acetate kinase. Microbiology 145:503-513.

44. Rey, D. A., A. Pühler, and J. Kalinowski. 2003. The putative transcriptional repressor McbR, member of the TetR-family, is involved in the regulation of the metabolic network directing the synthesis of sulfur containing amino acids in Corynebacterium glutamicum. J. Biotech. 103:51-65.

45. Sambrook, J., E. F. Fritsch, and T. Maniatis. 1989. Molecular cloning: laboratory manual, 2nd ed. Cold Spring Harbor Laboratory, Cold Spring Harbor, N.Y.

46. Schäfer, A., A. Tauch, W. Jäger, J. Kalinowski, G. Thierbach, and A. Pühler. 1994. Small mobilizable multi-purpose cloning vectors derived from the Escherichia coli plasmids pK18 and pK19: selection of defined deletions in the chromosome of Corynebacterium glutamicum. Gene 145:69-73.

47. Schaffer, S., B. Weil, V. D. Nguyen, G. Dongmann, K. Günther, M. Nickolaus, T. Hermann, and M. Bott. 2001. A high resolution reference map for cytoplasmic and membrane-associated proteins of Corynebacterium glutamicum. Electrophoresis 22:4404-4422.

48. Schultz, J., F. Milpetz, P. Bork, and C. P. Ponting. 1998. SMART, a simple modular architecture research tool: identification of signaling domains. Proc. Natl. Acad. Sci. USA 95:5857-5864.

49. Shaw, W. V. 1975. Chloramphenicol acetyltransferase from chloramphenicol-resistant bacteria. Methods Enzymol. 43:737-755.

50. Shiio, I., H. Momose, and A. Oyama. 1969. Genetic and biochemical studies on bacterial formation of L-glutamate I. Relationship between isocitrate lyase, acetate kinase, and phosphate acetyltransferase levels and glutamate production in Brevibacterium flavum. J. Gen. Appl. Microbiol. 15:27-40.

51. Shin, B. S., S. K. Choi, and S. H. Park. 1999. Regulation of the Bacillus subtilis phosphotransacetylase gene. J. Biochem. 126:333-339.

52. Stülke, J., and W. Hillen. 2000. Regulation of carbon catabolism in Bacillus subtilis. Annu. Rev. Microbiol. 54:849-880.

53. Sunnarborg, A, D. Klumpp, T. Chung, and D. C. LaPorte. 1990. Regulation of the glyoxylate bypass operon: cloning and characterization of $i c l R$. J. Bacteriol. 172:2642-2649.

54. Tegmark, K., A. Karlsson, and S. Arvidson. 2000. Identification and characterization of SarH1, a new global regulator of virulence gene expression in Staphylococcus aureus. Mol. Microbiol. 37:398-409.

55. Van der Rest, M. E., Lange, C., and D. Molenaar. 1999. A heat shock following electroporation induces highly efficient transformation of Corynebacterium glutamicum with xenogenic plasmid DNA. Appl. Microbiol. Biotechnol. 52:541-545.

56. Van Dyk, T. K., and R. A. LaRossa. 1987. Involvement of ack-pta operon products in $\alpha$-ketobutyrate metabolism by Salmonella typhimurium. Mol. Gen. Genet. 207:435-440.

57. Vasicova, P., Z. Abrhamova, J. Nesvera, M. Patek, H. Sahm, and B. J. Eikmanns. 1998. Integrative and autonomously replicating vectors for analysis of promoters in Corynebacterium glutamicum. Biotechnol. Tech. 12:743746.

58. Warren, W. A. 1970. Catalysis of both oxidation and reduction of glyoxylate by pig heart lactate dehydrogenase isoenzyme I. J. Biol. Chem. 245:16751681.

59. Weickert, M. J., and G. H. Chambliss. 1990. Site-directed mutagenesis of a catabolite repression operator sequence in Bacillus subtilis. Proc. Natl. Acad. Sci. USA 87:6238-6242.

60. Wendisch, V. F., M. Spies, D. J. Reinscheid, S. Schnicke, H. Sahm, and B. J. Eikmanns. 1997. Regulation of acetate metabolism in Corynebacterium glutamicum: transcriptional control of the isocitrate lyase and malate synthase genes. Arch. Microbiol. 168:262-269.

61. Yamamoto, K., and A. Ishihama. 2003. Two different modes of transcription repression of the Escherichia coli acetate operon by IclR. Mol. Microbiol. 47:183-194.

62. Yoshida, K.-I., K. Kobayashi, Y. Miwa, C.-M. Kang, M. Matsunaga, H. Yamaguchi, S. Tojo, M. Yamamoto, R. Nishi, N. Ogasawara, T. Nakayama and Y. Fujita. 2001. Combined transcriptome and proteome analysis as a powerful approach to study genes under glucose repression in Bacillus subtilis. Nucleic Acids Res. 29:683-692. 